\title{
An overview of the Chinese healthcare system
}

\author{
Baokang Yi \\ National Healthcare Security Administration, Beijing, China \\ Correspondence to: Baokang Yi. National Healthcare Security Administration, Beijing, China. Email: sophia811122@sohu.com.
}

Submitted Jan 12, 2021. Accepted for publication Jan 22, 2021.

doi: $10.21037 / \mathrm{hbsn}-2021-3$

View this article at: http://dx.doi.org/10.21037/hbsn-2021-3

The healthcare security system is an important institutional arrangement for reducing people's medical burden, improving people's well-being, and therefore maintaining social harmony and stability in China. The purpose of establishing a national medical security system is to relieve all people of their worries concerning illness and health care.

\section{The composition, coverage, and operational trend of China's national medical security system}

The national medical security system in China is a multilevel system, with the basic medical insurance (BMI) as the pillar and medical aid as the backup, and commercial health insurance, charitable donations, and medical mutual aid activities as supplementary services.

The BMI system serves two groups of people: employees and residents. Employees are enrolled in the employee basic medical insurance (EBMI) program, and non-working residents are enrolled in the residents basic medical insurance (RBMI) program. After being established in 2018, the National Healthcare Security Administration (NHSA) has continued to improve the national medical insurance system so that RBMI can be better integrated. As of September 2020, more than 1.35 billion people (over 95\% of China's population) are covered by one of the BMI programs, making it the world's largest healthcare security network. Among those covered, 337 million are covered by the EBMI, and 1.014 billion people are covered by the RBMI. The medical insurance fund is sustainable and growing. In 2019, the revenue of the national basic medical insurance fund (including maternity insurance) was CNY $¥ 2.44$ trillion, and the expenditure was CNY $¥ 2.09$ trillion (1).

Medical aid ensures all citizens have fair access to basic medical services by supporting the section of the low- income populace to participate in the BMI by subsidizing the medical expenses that they cannot afford. Since 2018, medical aid has benefited 480 million low-income citizens, helped reduce their medical burden by approximately CNY $¥ 330$ billion, implemented targeted poverty reduction measures for 10 million people in need who were impoverished due to illnesses, and ensured their basic medical security. Various social forces in the market also actively participate in supplementing the medical security system and have become an important element of the multilevel medical insurance system.

\section{Characteristics and advantages of China's healthcare security system}

The Chinese government has always regarded people's health and life safety as its basic responsibility, by providing the BMI as a public good for all Chinese citizens. However, a deficit in coverage still exists between China and other countries with developed social security systems. The proportion of total medical insurance financing is about $2.5 \%$ of China's GDP, which is not high, but it is generally compatible with the per capita GDP of US \$10,000 in China (2).

(I) Provide more. For one, government funding should be increased. From 2007 to 2019, government funding for medical security increased from CNY ¥91.3 billion $\mathrm{CNY} ¥ 800$ billion, and the proportion of government spending on medical insurance increased from $1.87 \%$ to $3.50 \%$. In 2020 , the government subsidy for resident medical security reached CNY $¥ 550$ per person (3). For another, focus should remain on the low-income population. Policies should lean towards the low-income population to ensure they have access to the BMI. The government continued to increase funding, and more than $99.9 \%$ of registered low-income citizens are now insured. The imbursement rate of hospitalization 
expenses has stabilized at around $80 \%$ for the lowincome population after the broad coverage provided by the triple security system: the BMI, critical illness insurance, and medical aid (4).

(II) Stay within economic capabilities. To ensure the sustainable balance of the fund, financial overcommitment should be avoided, and the planning should be informed by the current level of economic development. The fund should meet the basic needs of people, but it should avoid becoming a welfare fund.

(III) Reinforcing the administration of the security system. First, a nationally organized volume-based procurement and use of drug standard should be established. A total of 112 types of drugs were procured by China in three batches, with the costs decreasing by an average of $54 \%$, which saved CNY $¥ 53.9$ billion annually (5). Second, the catalog of medicines covered by the national health security system should be dynamically adjusted. Some obsolete drugs have been removed from the catalog to make room for drugs with more clinical value. Third, a reformation of medical insurance payment methods needs to be steadily implemented. In China, $97.5 \%$ of the local administrations have capped the total regional expense of medical insurance, and more than 30 pilot cities have launched diagnosis-related group payment systems. Fourth, medical organizations should be strictly supervised and unlawful practices should be heavily penalized. In the past 2 years, 330,000 unlawful organizations were suspended, and CNY $¥ 12.56$ billion in funds were retrieved. In 2019, 69 inspection teams were sent to 30 provinces across the country to conduct unannounced field inspections, and CNY $¥ 2.232$ billion in illegal funds were found.

\section{Reforming the drug pricing mechanism and promoting drug availability for patients}

The NHSA has implemented dynamic adjustments to the catalog of medicines covered by the national health security system and issued the Interim Measures on the Administration of Medicines under the Basic Medical Insurance (6). The interim measures are oriented towards meeting the basic medicinal needs of citizens and ensuring that drug expenditures are compatible with BMI funding. It is necessary to ensure a scientific, standardized, precise, and dynamic management of medical insurance drugs. For exclusively produced drugs, the price is determined by catalog access negotiation, which not only saves medical insurance funds but also significantly reduces the burden of cost to patients. The establishment of a dynamic adjustment mechanism can facilitate the timely inclusion of more effective drugs into the catalog.

An example of this has been in the management of hepatitisrelated drugs. In recent years, with the continuous efforts of the government, the price of drugs for viral hepatitis has been reduced substantially. In 2015, the annual treatment cost of hepatitis B antiviral drugs, tenofovir disoproxil fumarate (TDF) and entecavir, was about CNY $¥ 20,000$ and CNY $¥ 9,000$ per person, respectively. In 2018, after the "4+7" Pilot Program was launched, the annual treatment cost of TDF and entecavir was decreased to CNY $¥ 210-240$ per person. In 2019, after more cities were included in the pilot program, the cost of the two drugs was further decreased to CNY $¥ 70$. After the centralized procurement of entecavir, the total procurement volume was 3.5 times lower than that of the previous year in the " $4+7$ " pilot cities. The same year, the NHSA also negotiated and reimbursed a variety of hepatitis $\mathrm{C}$ oral drugs, so the outof-pocket costs paid by patients dropped by $95 \%$. With the substantial reduction in drug prices, the diagnosis rate and the availability of chronic hepatitis treatment were considerably improved, which enabled China to achieve the 2030 Sustainable Development Goal outlined by the World Health Organization: eliminating hepatitis as a public health threat.

\section{Building a multilevel medical security system to reinforce support capabilities}

In recent years, China's commercial health insurance premium income has developed rapidly at an annual growth rate of $30 \%$. In 2019, the premium income of commercial health insurance was CNY $¥ 706.6$ billion, which represented a year-on-year increase of $29.7 \%$ (7). To meet people's growing needs of health care in the new era, the government proposes to strengthen the triple security system, which includes basic medical insurance, critical illness insurance, and medical aid, and promote various complementary medical insurance programs for major and critical diseases. The development of commercial health insurance will be accelerated, more health insurance products will be offered, the individual income tax policies for commercial health insurance will be applied in a more effective way, and the scope of insurance products will be expanded (8).

\section{Seizing opportunities, meeting challenges, and promoting the high-quality development of medical security}

The year 2020 is the final year of 13th Five-Year Plan, and it 
is also the year to lay a good foundation for the 14th Five-Year Plan. Standing at this critical juncture, it is necessary to have a clear understanding of the challenges faced by health security.

The demographics of the Chinese population poses serious challenges to the sustainability of the fund. The number of people over the age of 60 will exceed 300 million people at the end of the 14th Five-Year Plan, and the ratio of employees to retirees will continue to decline (9). Another serious challenge is that communicable diseases and chronic diseases pose a "double burden" on China's medical insurance funds. There is still a gap between the healthcare security support and the medical expectations of citizens.

Medical security is highly relevant to the vital interests of the Chinese people as a whole. During the 14th Five-Year Plan period, the government will continue to promote the integrity of the multilevel medical security and guide the coordinated development of medical security, treatment, and medicine, so that the people can have more clear and accountable expectations for their health security and a greater sense of gain, healthy security and happiness in turn.

\section{Acknowledgments}

Funding: None.

\section{Footnote}

Provenance and Peer Review: This article was commissioned by the editorial office of Hepatobiliary Surgery and Nutrition. The article did not undergo external peer review.

Conflicts of Interest: The author has completed the ICMJE uniform disclosure form (available at https://hbsn. amegroups.com/article/view/10.21037/hbsn-2021-3/coif). The author has no conflicts of interest to declare.

Ethical Statement: The author is accountable for all aspects of the work in ensuring that questions related to the accuracy or integrity of any part of the work are appropriately investigated and resolved.

Open Access Statement: This is an Open Access article distributed in accordance with the Creative Commons Attribution-NonCommercial-NoDerivs 4.0 International License (CC BY-NC-ND 4.0), which permits the noncommercial replication and distribution of the article with the strict proviso that no changes or edits are made and the original work is properly cited (including links to both the formal publication through the relevant DOI and the license). See: https://creativecommons.org/licenses/by-nc-nd/4.0/.

\section{References}

1. National Healthcare Security Development Report 2019. Available online: http://www.nhsa.gov.cn/art/2020/6/24/ art_7_3268.html

2. What it means that the GDP per capita exceeds 10,000 US dollars. 2020. Available online: https://baijiahao.baidu. $\mathrm{com} / \mathrm{s}$ ? id $=1656049179746010782 \& w \mathrm{wr}=$ spider $\&$ for $=p c$

3. The Notice of Preparing Relevant Work of 2020 Residents Basic Medical Security, National Healthcare Security Administration, Ministry of Finance, State Taxation Administration. 2020. Available online: http://www.gov.cn/ zhengce/zhengceku/2020-06/19/content_5520571.htm

4. The "three-year action" of medical insurance poverty alleviation has reduced the burden of the poor by nearly 300 billion Yuan. 2020. Available online: http://www. xinhuanet.com/politics/2020-10/14/c_1126611738.htm

5. The state has made remarkable achievements in the centralized purchase of drugs, saving 53.9 billion yuan annually, and the average price of the purchased three batches of drugs has reduced more than half. 2020 . Available online: http://sh.people.com.cn/n2/2020/1014/ c138654-34348282.html

6. Interim measures for drug administration of basic medical insurance. 2020. Available online: http:// www.gov.cn/zhengce/zhengceku/2020-08/04/ content_5532409.htm

7. Data from China Banking and Insurance Regulatory Commission. Available online: http://www.cbirc.gov.cn/ $\mathrm{cn} /$ view/pages/index/index.html

8. Opinions on Deepening the Reform of Medical Security System, The CPC Central Committee, The State Council. 2020. Available online: http://www.gov.cn/ zhengce/2020-03/05/content_5487407.htm

9. Zheng Bingwen: China's elderly population will exceed 300 million at the end of the 14th Five-Year Plan. 2020. Available online: http://bgimg.ce.cn/xwzx/gnsz/ gdxw/202010/27/t20201027_35939625.shtml

(English Language Editor: J. Gray)

Cite this article as: Yi B. Healthcare security system in China: an overview. HepatoBiliary Surg Nutr 2021;10(1):93-95. doi: 10.21037/hbsn-2021-3 